\title{
Motor vehicle injuries in Qatar: time trends in a rapidly developing Middle Eastern nation
}

\author{
Ravinder Mamtani, ${ }^{1}$ Mohammed H Al-Thani, ${ }^{2}$ Al-Anoud Mohammed Al-Thani, \\ Javaid I Sheikh, ${ }^{3}$ Albert B Lowenfels ${ }^{4}$
}

${ }^{1}$ Department of Global and Public Health, Weill Cornell Medical College, Oatar ${ }^{2}$ Department of Public Health, Supreme Council of Health, Oatar

${ }^{3}$ Office of the Dean, Weill Cornell Medical College, Oatar ${ }^{4}$ Department of Surgery, New York Medical College, Valhalla New York, USA

\section{Correspondence to} Professor Ravinder Mamtani, Professor of Public Health and Associate Dean, Global and Public Health, Weill Cornell Medical College, Education City, PO Box 24144, Doha, Oatar; ram2026@qatar-med.cornell. edu

Accepted 15 September 2011 Published Online First 12 October 2011

\section{(2) UNLOCK:}

This paper is freely available online under the BMJ Journals unlocked scheme, see http:// injuryprevention.bmj.com/site/ about/unlocked.xhtml

\section{ABSTRACT}

Despite their wealth and modern road systems, traffic injury rates in Middle Eastern countries are generally higher than those in Western countries. The authors examined traffic injuries in Oatar during 2000-2010, a period of rapid population growth, focusing on the impact of speed control cameras installed in 2007 on overall injury rates and mortality. During the period 2000-2006, prior to camera installation, the mean (SD) vehicular injury death rate per 100000 was $19.9 \pm 4.1$. From 2007 to 2010, the mean (SD) vehicular death rates were significantly lower: $14.7 \pm 1.5(p=0.028)$. Non-fatal severe injury rates also declined, but mild injury rates increased, perhaps because of increased traffic congestion and improved notification. It is possible that speed cameras decreased speeding enough to affect the death rate, without affecting overall injury rates. These data suggest that in a rapidly growing Middle Eastern country, photo enforcement (speed) cameras can be an important component of traffic control, but other measures will be required for maximum impact.

\section{INTRODUCTION}

Road traffic injuries are a major component of the global burden of disease and disability and, in most countries, are the major cause of death during the first few decades of life. ${ }^{1}$ In the Middle East, in countries with high income levels, motor vehicle deaths are higher than in many other world regions where income levels are much lower.

During the last decade, Qatar, a member of the Gulf Cooperation Council, has exhibited rapid economic development and recently gained prominence by winning the bid for hosting the 2022 FIFA (Fédération Internationale de Football Association) World Cup. Qatar, a small country with a total land area of about $11600 \mathrm{~km}^{2}$, shares a common border with Saudi Arabia and is situated on a peninsula jutting into the Persian Gulf. The population, now estimated to be 1.6-1.8 million, has increased rapidly, as have the number of motor vehicles and licensed drivers. The estimated length of the road system is about $1600 \mathrm{~km}$, and about half of the roads are divided highways. To alleviate traffic congestion in Doha, the capital city, Qatar is increasing the number of divided roads. During the last decade, traffic death rates in Qatar increased steadily, reaching a level of 23 per 100000 in 2005 . In comparison, in Western Europe and North America, motor vehicle death rates ranged from about 5 to 10 per $100000 .^{1}$

In Qatar, until 2007, nearly two-thirds of all trauma-related deaths were caused by vehicular crashes and three-fourths of the victims were less than 50 years of age. ${ }^{2}$ Beginning in early 2007, much more stringent traffic control measures were implemented-an increase in fines for traffic violations, greater attention to seat belt use and an increase in the number of speed control cameras from 14 to 84 (a sixfold increase). Reports of the effectiveness of speed enforcement detection devices from Westernised countries (Europe, North America and Australia) have shown some beneficial impact on reducing road traffic injury and death rates, ${ }^{3}$ but there are limited data on the use of photo enforcement cameras in other countries of the Middle East.

The aim of this study was to examine time trends in motor vehicle injuries in Qatar between 2000 and 2010, with particular emphasis on the impact of photo enforcement cameras.

\section{METHODS}

For this report, we relied upon yearly data collected and stored by the Qatar Supreme Council of Health during the years 2000 to 2010 . These data are the basis of comprehensive health reports published annually by the Health Information Section of the Supreme Council of Health. Additional information about traffic control measures was obtained from the traffic department of the Ministry of Interior.

We considered any death within a 30-day period after a motor vehicle injury as being caused by that injury. Included in this category are drivers, passengers and occupants of trucks and buses, as well as pedestrians and bicyclists injured by motor vehicles. In addition to motor-vehicle-associated deaths, we also recorded non-fatal injuries classified as severe (requiring hospitalisation) or mild (not requiring hospitalisation)

The traffic department supplied information on the yearly number of tickets issued for traffic violations. By dividing the number of yearly tickets by the total population, we obtained populationbased estimates of the frequency of traffic violations. However, these cannot be considered true rates because many individuals had received more than one ticket. Tickets issued as a result of activity collected by the photo enforcement system were only for speeding or for driving through red lights and not for other traffic violations.

We used means, standard deviations and Student $t$ test to compare the frequency of motor vehicle injuries and tickets issued for traffic violations before and after speed cameras were installed in 2007. All statistical tests were two-sided. The project was approved by the Weill Cornell institutional review board. 
Table 1 Traffic injury data: Qatar 2000-2010

\begin{tabular}{|c|c|c|c|c|c|c|c|c|}
\hline \multirow[b]{3}{*}{ Year } & \multirow[b]{3}{*}{ Population } & \multirow[b]{3}{*}{$\begin{array}{l}\text { Total } \\
\text { injuries }\end{array}$} & \multirow{3}{*}{$\begin{array}{l}\text { Tickets } \\
\text { issued, } n \\
\text { (n/100 persons) }\end{array}$} & \multicolumn{5}{|c|}{ Injury rate/100 000} \\
\hline & & & & \multicolumn{2}{|c|}{$\begin{array}{l}\text { Non-fatal } \\
\text { injuries }\end{array}$} & \multicolumn{3}{|c|}{ Fatal injuries } \\
\hline & & & & Mild & Severe & $<40$ & $\geq 40$ & $\begin{array}{l}\text { All } \\
\text { ages }\end{array}$ \\
\hline 2000 & 613967 & 1216 & $52132(8.5)$ & 115 & 69 & - & - & 14 \\
\hline 2001 & 643365 & 1525 & $46962(7.3)$ & 145 & 75 & 18 & 16 & 17 \\
\hline 2002 & 676497 & 1536 & $58422(8.6)$ & 143 & 67 & 15 & 22 & 17 \\
\hline 2003 & 713858 & 1435 & 93911 (13.1) & 123 & 57 & 21 & 22 & 21 \\
\hline 2004 & 798060 & 1540 & 110803 (13.9) & 133 & 39 & 20 & 21 & 21 \\
\hline 2005 & 906117 & 1713 & 172841 (19.1) & 116 & 50 & 24 & 19 & 23 \\
\hline 2006 & 1042951 & 1898 & $281794(27.0)$ & 112 & 44 & 25 & 27 & 26 \\
\hline 2007 & 1218252 & 2729 & $689257(56.6)$ & 165 & 43 & 15 & 21 & 16 \\
\hline 2008 & 1448484 & 4592 & 632194 (43.6) & 262 & 39 & 13 & 26 & 16 \\
\hline 2009 & 1638644 & 4654 & 796017 (48.6) & 237 & 33 & 13 & 16 & 14 \\
\hline 2010 & 1699435 & 4884 & $1057851(62.4)$ & 241 & 33 & 11 & 17 & 13.4 \\
\hline
\end{tabular}

\section{RESULTS}

During the study period, the overall population of Qatar increased from 614000 to 1.7 million; about $75 \%$ of the population were $<40$ years of age. There were a total of 27722 motor vehicle injuries, including 1991 deaths (table 1). Tickets issued for traffic violations increased dramatically during the study period, from about 52000 in 2000 to over a million in 2010 .

\section{Injury rates: time trends}

Changes in injury rates differed by degree of severity. Mild injury rates exhibited inconsistent changes until 2007, when there was a sudden and sustained increase. Severe, that is, non-fatal injuries requiring hospitalisation decreased steadily throughout the period. In contrast, fatal injuries showed a steady increase until speed camera installation in 2007, when there was a sharp drop. During the period 2000 to 2006, the mean (SD) vehicular injury death rate per 100000 was 19.9 \pm 4 .1; from 2007 to 2010, the mean (SD) vehicular death rates were significantly lower: $14.7 \pm 1.5(\mathrm{p}=0.043)$ (figure 1$)$. The decline in fatal injury rates from 2007 to 2010 was restricted to persons $<40$ years of age; there was no significant change in fatal injury rates for older persons (figure 2).

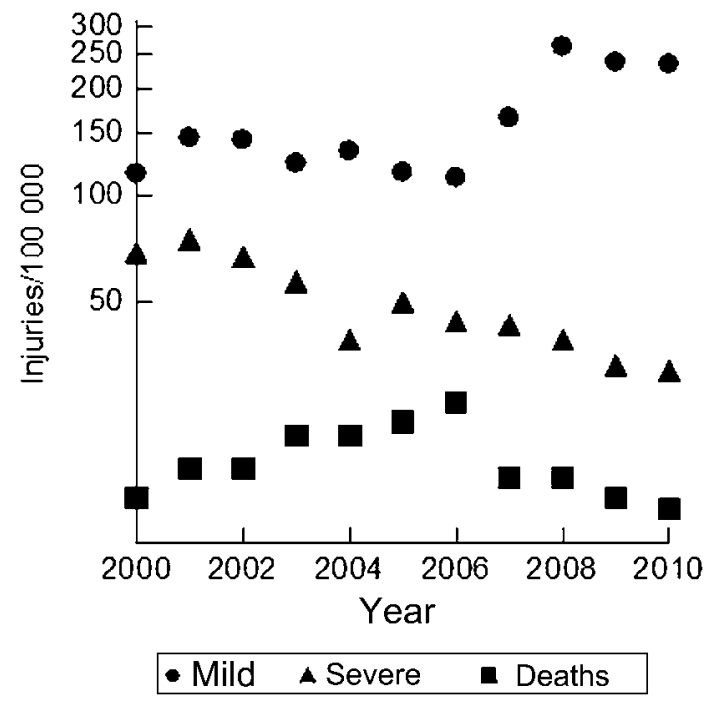

Figure 1 Yearly vehicular injury rates per 100000 in Oatar during the period 2000-2010. Circles indicate injuries not requiring hospitalisation, triangles denote injuries requiring hospitalisation and squares indicate injuries resulting in death. Log scale was used for the vertical axis.

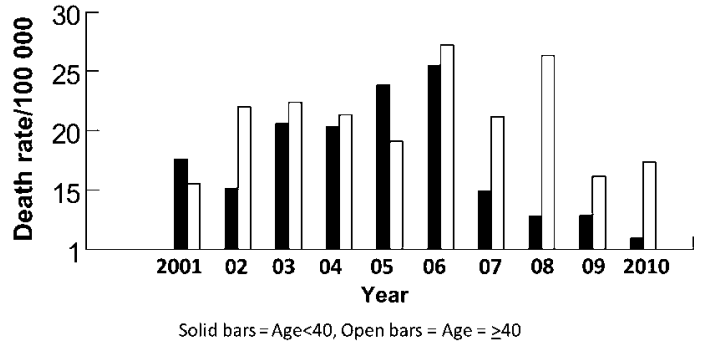

Figure 2 Yearly vehicular death rates per 100000 in Qatar during the period 2001-2010 stratified by age. Filled bars indicate rates in persons $<40$ years, while open bars denote rates in persons $\geq 40$ years. Agespecific death rates were unavailable for the year 2000 .

Ticketing rates for traffic violations: time trends

After the installation of photo enforcement cameras in early 2007, there was a marked increase in the number of tickets issued: prior to camera installation, the mean (SD) number of tickets issued per 100 population was $13.9 \pm 7.1$ compared to $52.4 \pm 7.7$ after camera installation $(p \leq 0.001)$. The increase in tickets for traffic violations corresponded with the decreased death rate from traffic injuries (figure 3 ).

\section{DISCUSSION}

This study of traffic injuries in a small Middle Eastern country was conducted during a period of rapid population growth leading to an approximately threefold increase in the number of registered vehicles and a much higher increase in the number of licensed drivers-a possible explanation for the increase in the number of mild, non-fatal injuries.

During the study period, the traffic department of the Ministry of Interior authorised an increase in the number of cameras from 14 to 84, with nearly all the increase taking place in 2007. As a result, tickets issued increased dramatically and were associated with a significant decrease in the motor vehicle injury death rate. With respect to the role of traffic tickets, we observed what appears to be a threshold effect: below 40 per 100 , an increase in the number of tickets had no impact on death

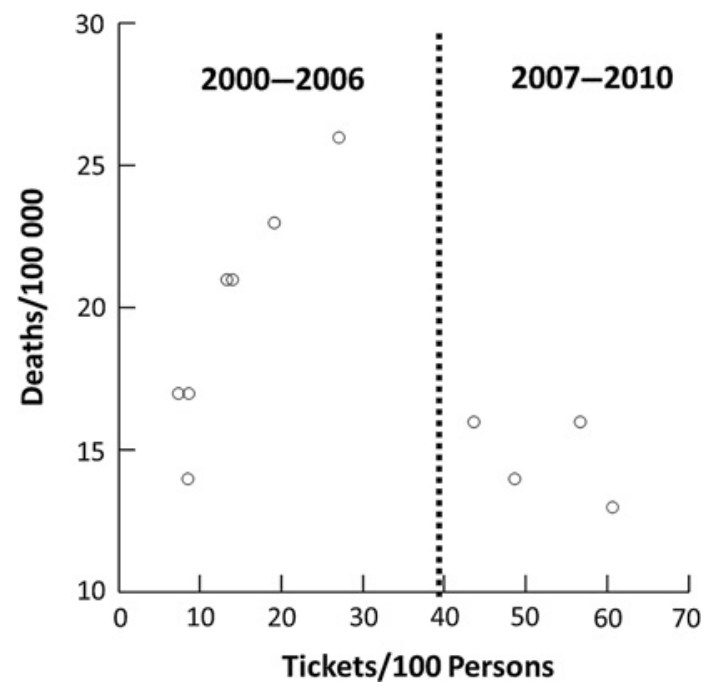

Figure 3 Vehicular death rates in Qatar plotted against number of tickets issued per 100 persons in two time periods: before and after 2007. 


\section{What is already known on the subject}

Throughout the world, road traffic injuries are a major cause of morbidity and mortality.

- Middle Eastern countries have high motor vehicle injury rates.

- In Western countries, speed cameras have been proven to be effective in controlling traffic crashes, but they have not been evaluated in the Middle East.

\section{What this study adds}

- In Qatar, a country with recent rapid population and economic growth, road traffic deaths increased steadily during the first several years of the 21 st century.

- After installation of speed control cameras in 2007, there was a significant drop in motor vehicle deaths.

- When combined with additional traffic control measures, speed control cameras in non-Western countries can help reduce the burden of road traffic injuries.

rate. However, above this level, there was a profound drop in traffic deaths, which has persisted over a 4-year period (figure 3).

A major weakness of the study is that we cannot be sure how much of the reduction in death rates was caused by the new camera surveillance system. Although the sixfold increase in the number of installed cameras was associated with a highly significant increase in the number of traffic tickets issued, it is possible that other factors such as an increase in the amount of fines, increased use of seat belts by motor vehicle occupants, more effective triage and transportation or improved patient care may have contributed to the lowered death rates.

Another weakness of this study is that although traffic deaths and serious injuries declined during the study period, the incidence of mild injuries not requiring hospitalisation increased. We believe that this could be related to improved notification of mild injuries or to the rapid population growth resulting in increased traffic density. Another explanation is that speed cameras decreased speeding enough to reduce the death rate, without affecting less severe injuries.

Opinions about the effectiveness of speed control cameras are conflicting. ${ }^{3-6}$ Most reports resemble our study, which used a before/after design. In Qatar, photo cameras appear to have had the greatest impact on fatal injuries rather than on severe or mild injuries, and decreases in motor vehicle deaths were more noticeable in younger persons, who constitute three-fourths of the population.

In 2008, of persons with serious injuries, about 20\% were native Qataris, which is approximately equal to the proportion of Qataris in the population. Therefore, we believe that both the native and the non-native groups have about the same risk of motor vehicle injury. This is reassuring because many of the non-Qatari inhabitants come from countries where driving regulations differ from Qatar's.

How do current death rates in Qatar compare to other regions? In 2009, many Western countries such as Spain, Ireland, Austria, France, Germany, UK, Sweden, Norway and Australia had road traffic death rates ranging from 5 to 10 per 100000 , lower than the 2009 rate of 14 per 100000 for Qatar. This suggests that appropriate well-enforced laws have the potential for further reducing traffic death rates. This could be important in Qatar, where road traffic injuries have been considered an epidemic $^{7}$ and more than $25 \%$ of drivers have been involved in a road traffic crash. ${ }^{8}$

Acknowledgements We thank Dr Tarek Abdelrahaman El-Sayed, Dr Mamoun Nader Rabee and Dr Kholood Ateeq Al Mutawa from the Department of Public Health, Supreme Council of Health, who helped obtain and check data, and Brigadie Mohd A Al-Malki, General Secretary of the National Committee for Traffic Safety, Ministry of Interior, Oatar, and his team for providing information on traffic safety and for their insight on injury data.

\section{Competing interests None.}

Ethics approval Ethics approval was obtained from the Institutional Review Board of Weill Cornell Medical College in Oatar.

Provenance and peer review Not commissioned; externally peer reviewed.

\section{REFERENCES}

1. Global status report on road safety: time for action. Geneva: World Health Organization 2009, 2011.

2. Al-Dulimi HH, Abosalah S, Abdulaziz A, et al. Trauma mortality in the state of Qatar, 2006-2007. J Emergency Med Trauma Acute Care 2010;9:19-25.

3. Wilson C, Willis C, Hendrikz JK, et al. Speed cameras for the prevention of road traffic injuries and deaths. Cochrane Database Syst Rev 2010;(11):CD004607.

4. Pilkington $\mathbf{P}$, Kinra S. Effectiveness of speed cameras in preventing road traffic collisions and related casualties: systematic review. BMJ 2005: 330:331-4

5. Perez K, Mari-Dell'Olmo M, Tobias A, et al. Reducing road traffic injuries: effectiveness of speed cameras in an urban setting. Am J Public Health 2007;97:1632-7.

6. Belin MA, Tillgren P, Vedung E, et al. Speed cameras in Sweden and Victoria, Australia-a case study. Accid Anal Prev 2010;42:2165-70.

7. Bener A. The neglected epidemic: road traffic accidents in a developing country, State of Oatar. Int J Inj Contr Saf Promot 2005:12:45-7.

8. Burgut HR, Bener A, Sidahmed $\mathrm{H}$, et al. Risk factors contributing to road traffic crashes in a fast-developing country: the neglected health problem. Ulus Travma Acil Cerrahi Derg 2010;16:497-502.

\section{Correction}

Hong-lin Chen, Kun Liu, Qin-Sheng You. Attention should be paid to preventing knee injury in tai chi exercise. Inj Prev 2011;17:286-287. doi:10.1136/injuryprev-2011-040027. This article was published in print with the incorrect DOI. The correct DOI is $10.1136 /$ injuryprev-201140027. This was the DOI published online first and therefore the DOI of record.

Injury Prevention 2012:18:132. doi:10.1136/injuryprev-2011-40027 